\title{
Fora a cidade, o último coração do sonho, em Al Berto
}

\author{
Mônica Simas \\ Universidade de São Paulo \\ APOIO CNPq
}

\begin{abstract}
Resumo
Este trabalho busca analisar o poema "prefácio para um livro de poemas", de Al Berto, relacionando questões que envolvem a literatura, o espaço, a modernidade com o território da tradição, menos observado pela crítica contemporânea. A leitura parte do princípio de que o poema situa-se em um espaço intermédio, entre a intensidade da emoção que reside nos restos de metáforas expressivas do passado, por um lado, e a exatidão, tal como a definiu Italo Calvino, por outro. É minha hipótese de leitura que o poema mostre um salto em direção a uma terra coletiva e ancestral que resguarda o espaço cultural ibérico lírico.
\end{abstract}

Palavras-chave: tradição e modernidade; poesia portuguesa contemporânea; poesia e espaço.

\begin{abstract}
This work tries to analyze the poem "prefacio para um livro de poemas [preface to a book of poems]", by Al Berto, relating issues that involve literature, space, modernity with the territory of tradition, less observed by contemporary critics. The reading assumes that the poem lies in an intermediate space, between the intensity of emotion that resides in the remains of expressive metaphors as in the past, on the one hand, and the exactness, as defined by Italo Calvino, on the other. It is my hypothesis of reading that the poem shows a leap towards a collective and ancestral land that shelters the Iberian lyrical cultural space.
\end{abstract}

Keywords: tradition and modernity; contemporary Portuguese poetry; poetry and space.

Recebido em: 30/04/19 Aprovado em: 02/08/19

O impacto que "prefácio para um livro de poemas", de Al Berto (2006), causa sobre as questões que envolvem a literatura, a poesia, o espaço e também entre a poesia e a morte podem surpreender o leitor porque, ao fazer um balanço de questões contemporâneas, já bastante tratadas pela crítica, aprofunda a habitação potencial de um território da tradição, menos observado, que finca raízes em processos históricos da cultura. Sendo estrangeiro na própria língua, como mostra Golgona Anghel (2006), amplifica as sensibilidades para a cultura local, e sinto eu a necessidade de falar sobre essas circunstâncias para as quais a escrita do poema se abre. 
Às vezes, parece-me que a modernidade, em seus ritos obsessivos, foi caminhando para a impossibilidade de se pensar fora de determinadas contradições. Os modernismos, em várias de suas manifestações, elegeram, por exemplo, uma fórmula — tradição versus novo para estigmatizar a linguagem do passado, fincando-lhe a bandeira de uma mesmidade. Como todo mitema, este provoca, de vez em quando, algumas descobertas do novo no antigo, em uma situação invertida àquela em que Octávio Paz (1984) acabou por definir como tradição moderna (a repetição do novo). O problema é que os mitemas tendem a ir se acumulando, uns sustentando outros até que alguém atraentemente venha desler as formulações. Parece-me que Jauss (1996) tenha trazido algumas contribuições importantes em seu ensaio "Tradição literária e consciência atual da modernidade", da mesma forma que me interessa observar como alguns poetas e escritores dissolvem posições cristalizadas. Hoje, as posições lineares e progressistas bem como perspectivas deterministas dos fenômenos parecem ter cedido a visões policêntricas. Por isso, antes mesmo de comentar o poema que derivou as minhas reflexões, gostaria de rever brevemente o percurso que uniu a noção de modernidade à cidade e como essa relação funcionou de forma paradigmática para se ler a literatura.

\section{A literatura e o espaço citadino}

A cidade foi um núcleo forte nas redes textuais da literatura moderna. A legibilidade citadina tornou possível a criação de diversos eixos interpretativos, como, por exemplo, o de Walter Benjamin (1995), no qual, através de uma reconceituação da mônada, definindo-a por dois valores síntese - condensação e tensão - gerou uma imagem dialética da cidade. $\mathrm{Na}$ interpretação de Olgária Matos (1993), a mônada pôde indicar que a cidade é um mundo em miniatura que funde uma cidade da superfície com outra labiríntica. A tensão entre os caminhos que percorrem essas duas cidades se intensificou com a perda da memória como guia do homem moderno (ROUANET, 1990) e a sua inevitável ruptura com a experiência, por conta da velocidade e dos choques vivenciados, dramatizou a fragilidade com que as pessoas passaram a viver o tempo. Vários poetas, escritores e artistas permitiram-se circular e se misturar com os signos da cidade, buscando a sua legibilidade em torno dessas tensões. Baudelaire se fez esgrimista para registrar tudo aquilo que é provisório; Cesário Verde pintou de cores a vida citadina; também dramatizou amarguras, em ângulos agudos, falando de asperezas e da solidão finissecular lisboeta. Ítalo Calvino, o geômetra de As cidades invisíveis (1990), definiu a cidade como um símbolo de exatidão na medida em que poderia exprimir uma outra tensão, aquela entre a racionalidade e o emaranhado das existências humanas. O cristal e a chama, como forças opostas da exatidão, acabariam por ser duas imagens a serem evocadas, eventualmente, neste milênio, para concentrar as apostas do escritor (CALVINO, 1998).

Seja como esgrimista ou como flaneur, seja como trapeiro que recolhe imagens descartadas, tal como propõe o filme $O$ céu de Lisboa (1984), de Wim Wenders, seja como geômetra, todas 
essas figuras alegóricas se friccionaram, de certa forma, com as dimensões econômicas e dos meios de comunicação de massa, buscando resistir ao esvaziamento dos sentidos da linguagem. Não importa que tenham ultrapassado aquelas categorias duais, muitas vezes referidas como espaço de vício ou de virtude, indo além do bem e do mal, para usar uma expressão de Carl Shorske (1987), o fato é que os escritores e os poetas, especialmente, ainda apresentavam uma vontade de conhecer ou, então, de expor uma referencialidade citadina. Em tempos recentes, no entanto, a ênfase da reflexão poética tem recaído sobre a desconstrução da ideia do poema como lugar de qualquer imposição ou solução. João Barrento (2014) desinstala a hipótese de uma relação entre poesia e utopia, por exemplo, para reinstalá-la em terreno incerto do que chama de "corpo agora", uma espécie de potência, de vivência no presente e, portanto, sem uma ideia de futuro. E a partir de uma epígrafe, que lhe é fornecida por Maria Gabriela Llansol — "Os poetas vêem, e anunciam a geografia imaterial por vir" (apud BARRENTO, 2014, p. 17) —, passa a refletir sobre essa zona da espécie terrestre, ou seja, da paisagem humana que ele vê distribuída por vagabundos, formadores, construtores e poetas. Sem os transformar em figuras de utopia, ou pelo menos, daquela utopia calcada na possibilidade de dar uma explicação sobre o mundo, nem apresentar uma intensidade emocional, para o filósofo e escritor, desfaz-se a possibilidade de construir o poema com uma linguagem metafórica expressiva. O poema é, na sua reflexão, uma hipótese, um objeto de rigor e, mais do que afirmação do mundo literário, é um modo de existir; também lugar de exílio, "num mundo às avessas (dirão alguns poetas) que com ele entrou em guerra" (BARRENTO, 2014, p. 36). Para ele, isso faz sentido porque paradoxalmente permite tocar tudo aquilo que os dias de hoje recusam como sentido. Como já afirmava Wim Wenders (1994, p. 181) sobre a experiência urbana, "as cidades não contam mais histórias, mas podem contar algo sobre a História", podem, portanto, nos dias de hoje, tocar a aparência de um mundo sem sentido, se for o caso. João Barrento (2014) afirma, ainda, que os poetas podem ver e anunciar uma outra ordem; que o poema vai à frente do seu tempo, enfrentando a cegueira do mundo. Para ele, o poema "autenticamente moderno" nasceu "sem arroubos expressivos" e "sem os excessos da emoção", ou seja, buscando objetivar a expressão. Esse fenômeno está longe de ser recente; veio sendo concretizado desde a ruptura com a oralidade, pois, no momento em que a poesia deixou de ser um continuum e passou a ser um objeto escrito, a precisão das palavras mostrou-se cada dia mais exigente. Italo Calvino (1998), na sua proposta "Exatidão", aponta ao fato de que mesmo para se apreciar a beleza do vago e do indeterminado são necessárias meticulosas expressões que iluminam a cena e testemunham a necessidade de pormenores ou de evidentes destaques sobre um fundo homogêneo.

Assim, observo que o poema de Al Berto (2006, p. 35), "prefácio para um livro de poemas", escolhido para leitura, parece situar-se em um espaço intermédio, entre a emoção e o resíduo de metáforas expressivas, por um lado, e a exatidão que, por sua vez, é feita, como foi definida por Italo Calvino, de uma oposição - a chama e o cristal. Observo também que o poeta 
nunca se esquivou dos chamados "arroubos expressivos" ou dos "excessos da emoção", o que não impede, de jeito nenhum, dizer que a sua poesia seja rigorosa. Da mesma forma, as figuras da chama e do cristal parecem ser deslocadas para um espaço outro que não a cidade. Entendo que esta seja uma particularidade que o diferencia de outros escritores da geração de 1970, marcados por retornarem a certa narratividade e substituírem imagens impressivas por outras perceptivas (MARTELO, 2007). Se os lastros de narratividade compõem o poema de Al Berto, também estarão presentes recursos da experimentação textual e, ainda, o tal resíduo potencial do lirismo, tão "escorraçado" nas discussões sobre a poesia moderna. Os versos da segunda estrofe — "as cidades (como em todos os livros que li) ardem. incêndios que destroem o último coração do sonho" - mostram uma distopia flagrante, mas que através de uma metamorfose pode saltar para outra direção — "mas aquele que se veste com a pele porosa da sua própria escrita olha, absorto, a laranja”. Teria a laranja uma relação com o último coração do sonho? "As cidades (em todos os livros que li) ardem" não só já referem as cidades escritas mas também a impossibilidade de serem elas o espaço possível para aquele "que se veste com a pele porosa da sua própria escrita". O espaço em que o estilo atrelado ao orgânico, à vida, ao emaranhado das existências, tal como foi o da experiência de Italo Calvino, já não poderia prevalecer. Mas será que as oposições com as quais a cidade escrita foi se definindo só podem ser vislumbradas na malha urbana? Também as cidades todas lidas, talvez, ardam em interesses que não são os daquele que vive e sente com os poros a sua escrita, ou seja, como disse João Barrento (2014, p. 19), a vida-escrita não tem lugar "num mundo que perdeu essas faculdades [ver e ouvir o mundo vivo] e já só sobre-vive". Nem tampouco a cidade poderia ser identificada com a associação da proliferação de signos, muitas vezes, relacionada a uma erótica. Parece que o "último coração do sonho", o espaço do desejo, está sujeito à destruição das cidades. Ou haverá um escape?

É como legente que busco ler este poema, ativando e prolongando-o pelo desdobrar dessas duas metáforas - o coração do sonho e a laranja — , partindo do princípio de que tal como a epígrafe, escolhida por João Barrento, de Llansol, Al Berto, em sua singularidade, também "conhece bem o potencial transformador e humanizador da poesia" (BARRENTO, 2014, p. 17). Além disso, é minha hipótese que a sua poesia, ao carregar uma dimensão oral, migre para um mundo anterior às oposições que a modernidade marcou como "campo" versus "cidade", por exemplo. Pelo "esvaziamento desamparado na noite sem fundo" de que fala Golgona Anghel (2012), com relação aos diários do escritor, no poema, existe um salto em direção ao rumor da língua que só se pode ouvir no espaço fora, uma dimensão do próprio espaço literário, o que envolve uma solidão essencial, segundo Blanchot (1987). O poema empurra a uma dimensão em que a linguagem é recriada. De forma complementar, se o seu estilo "é algo claramente auditivo", como bem sublinha a poeta, no ensaio que antecede a antologia de poemas, O último coração do sonho (AL BERTO, 2006), por outro lado, no silêncio imenso, o poema abre-se, através das duas metáforas citadas, ao inconsciente coletivo e ancestral, fazendo emergir uma soma de vozes. 
Como já foi dito, para Golgona Anghel, a oralidade em Al Berto revela que a poesia precisa de uma voz que ele acaba por forjar, tornando-se estrangeiro na própria língua. Para mim, ao ler o poema citado, o gaguejar, criando uma língua dentro da língua também reterritorializa uma tradição literária que demarca um espaço bem conhecido, que é o espaço nativo ibérico forjado na lírica. E alguns dos ritornelli que aparecem no "prefácio para um livro de poemas", talvez, caminhem para restos musicais da literatura do passado e de sua dimensão simbólica. Sendo assim, observo que o título do poema, ao mesmo tempo que aponta para a metalinguagem, um tipo de produção textual - o prefácio - a indicar que vai introduzir ou explicar o conteúdo de uma obra poética, pode ser lido numa outra chave que é a do pré face, uma face anterior, um rosto enigmático que antecede a face daquilo que é o próprio do homem atual, como uma camada subterrânea. Por isso, no deambular destas palavras, "fora a cidade", parte do título desta minha deambulação, é uma expressão menos comum do que seria o "fora da cidade"; no entanto, ela possibilita que eu marque a hesitação diante do paradigma que estruturou a recepção da cidade escrita moderna, dizendo respeito apenas ao citadino, ou melhor, a uma imagética referencial. Ou seja, "o coração do sonho", em sua exatidão, poderá existir, provavelmente, mesmo que as cidades, como escritas em todos os livros lidos, ardam, desde que se desloque para uma outra região que envolve outro aporte simbólico. É interessante observar que, neste poema, diferente de outros, Lisboa ou Sines não estão referidas. O poema de Al Berto mostra que, talvez, seja possível habitar de uma nova velha maneira a cultura, a terra, a própria cidade em sua tensão de chama e cristal. Para seguir, no entanto, vou compartilhar o poema na íntegra porque só assim o leitor pode perceber o seu movimento, as suas injunções e também estabelecer a sua leitura própria. O recorte em um caminho de argumentação é sempre muito perigoso:

prefácio para um livro de poemas

conheci um homem que possuía uma cabeça de vidro, víamos - pelo lado menos sombrio do pensamento - todo o sistema planetário. víamos o tremelicar da luz nas veias e o lodo das emoções na ponta dos dedos. o latejar do tempo na humidade dos lábios. e a insónia, com seus anéis de luas quebradas e espermas ressequidos. as estrelas mortas das cidades imaginadas. os ossos tristes das palavras.

a noite cerca a mão inteligente do homem que possui uma cabeça transparente. em redor dele chove.

podemos imaginar uma chuva espessa, negra, plúmbea. depois, o homem abre a mão, uma laranja surge, esvoaça. as cidades (como em todos os livros que li) ardem. incêndios que destroem o último coração do sonho. mas aquele que se veste com a pele porosa da sua própria escrita olha, absorto, a laranja. 
a queda da laranja provocará o poema?

a laranja voadora é, ou não é, uma laranja imaginada por um louco?

e um louco, saberá o que é uma laranja?

e se a laranja cair? o poema? e o poema com uma laranja a cair?

o poema em forma de laranja?

e se eu comer a laranja, estarei a devorar o poema? a ficar louco?

e a palavra laranja existirá sem a laranja?

e a laranja voará sem a palavra laranja?

e se a laranja se iluminar a partir do seu centro, do seu gomo mais

secreto, e alguém a esquecer no meio da noite - servirá o brilho da laranja para iluminar as cidades há muito mortas?

e se a laranja se deslocar no espaço - mais depressa que o pensamento, e muito mais devagar que a laranja escrita — criará uma ordem no caos?

o homem que possui uma cabeça de vidro habita o lado de fora das muralhas da cidade.

foi escorraçado

e na desolação das terras, noite dentro, vigia os seus próprios sonhos

e pesadelos. os seus próprios gestos - e um rosto suspenso na solidão.

onde mora o homem que ousou escrever com a unha na sua alma,

no seu sexo, no seu coração?

e se escreveu laranja na alma, a alma ficará mais saborosa?

e se escreveu laranja no coração, a paixão impedi-lo-á de morrer?

e se escreveu laranja no sexo, o desejo aumentará?

onde está a vida do homem que escreve, a vida da laranja, a vida do poema - a Vida, sem mais nada - estará aqui?

fora das muralhas da cidade?

no interior do meu corpo? ou muito longe de mim — onde sei que

possuo uma outra razão ... e me suicido na tentativa de me transformar

em poema e poder, enfim, circular livremente.

(AL BERTO, 2006, p. 35-36)

\section{"O coração do sonho" e a "laranja"}

O poema apresenta uma estrutura multifacetada, com uso de sequencialidade de frases, cortes e repetições, o que lembra alguns dos cadáveres esquisitos e outros jogos surrealistas como o inventário, com riqueza de interrogações em torno de uma palavra, que, em um primeiro momento, parece arbitrária. De novo, é Golgona Anghel (2006) quem reconhece no estilo de Al Berto uma sintaxe própria que põe a língua a delirar e também o uso do ritornello, já citado, conceito deuleuziano cuja explicação resgata aquelas cantigas que as crianças cantam em um momento de estranhamento para se acalmarem; uma repetição que pode dar sustentação, trazer alguma terra em meio ao caos. O que está em jogo parece ser a vontade de assumir uma linguagem que se edifica sobre suas ruínas para realizar reflexões sobre o desejo, o sexo, a alma, retornando até o encantamento absoluto, fazendo o escritor sair da vida, suicidar-se, 
deixando-se nos rastros da escrita, "circular livremente". Penso este suicidar-se como aquela possibilidade de o escritor viver o fundo de ausência que não é pura imaginação, mas um chamamento para fora da existência, tal qual Blanchot (1997) nos revela.

Ao destacar essas duas expressões — "coração do sonho" e "laranja" —, sublinho que a palavra "laranja" fora do seu uso comum, usada para disparar as interrogações entre o mundo e a linguagem - "e a palavra laranja existirá sem a laranja?/ e a laranja voará sem a palavra laranja?” (AL BERTO, 2006, p. 36) —, implica algo além do seu significado imediato dicionarizado, mas, além disso, pode ser vista como um "resto" de outros significados que ela trouxe à literatura. Essa palavra, submersa no limiar da consciência, liga todos os possíveis acontecimentos do poema, numa relação de equivalência com a vida e a escrita, já que na última estrofe, ela participa dos segmentos paralelos — "onde está a vida do homem que escreve, a vida da laranja, a vida/ do poema - a Vida, sem mais nada - estará aqui? Por isso, penso que olhar "absorto" essa laranja possa resguardar o "coração do sonho" que vai sendo destruído com as cidades que ardem. Os sonhos não são somente produto do acaso, mas estão relacionados a pensamentos e problemas conscientes e ao inconsciente individual e coletivo. $\mathrm{O}$ sonho, segundo Carl Jung (1964), pode mostrar o que ao homem pertence e o que dele se afasta. A simulação da dimensão subjetiva do sonho ou a incorporação dele no texto deixa prevalecer uma outra razão. Nesse ponto, é interessante regressar a Italo Calvino (1998), porque, ao mesmo tempo que a dimensão subjetiva parece sobressair à língua no seu uso mais comum, é com a exatidão da palavra - "laranja" — que as operações indagativas podem se conectar. Ainda como indicou Golgona Anghel (2006, p. 27), para estar em casa tal como o ritornello tenta promover é preciso "traçar um círculo em torno do centro frágil e incerto, organizar um espaço limitado". A "laranja" é essa palavra que pode organizar o espaço de reflexão sobre a escrita, mas, a meu ver, longe de uma arbitrariedade ocasional, ela é extraída do simbolismo tradicional da lírica ibérica, evocando uma dimensão amorosa e erótica que aparece subliminar no decorrer dos procedimentos do poema e um pouco mais evidente na parte final — "e se escreveu laranja no sexo, o desejo aumentará?" (AL BERTO, 2006, p. 36).

Primeiro, quero lembrar com María Zambrano (2000) que a metáfora do coração, outra palavra a que Al Berto não se furta em usar, apesar de ter sido até lugar do pensamento em Aristóteles, tudo em alguma poesia e nas religiões, e ainda continuar a sê-lo para as criaturas iletradas, especialmente nas latitudes do mediterrâneo (também do Portugal do sul) e de ter subido à superfície da história nos dois Romantismos europeus, inclusive, fixando a expressão "coração em chamas", sumiu, absorvida pelo tempo e também pela cultura racionalista, como que levada pelas águas do rio, ficando por baixo da areia, na expressão da autora, à espera de se tornar outra vez visível. A visão do coração, em vez da luz intelectual, liga-se a uma vida secreta e misteriosa, a um dentro obscuro que às vezes se abre. Este abrir-se é, para a filósofa, a sua maior nobreza porque é uma interioridade "que se oferece para continuar a ser interioridade, 
sem a anular" (ZAMBRANO, 2000, p. 23). Essa "é a definição de intimidade", continua. O "coração do sonho", portanto, pressupõe uma intimidade, o gesto de abrir-se, desejante da interioridade afetiva. Que esta intimidade subjetiva pertença ao domínio do desejo, do sexo, do amor revela-se através do instrumento utilizado para dar o salto, a laranja.

No segundo capítulo, Golden Lamps in a Green Night, do instigante livro de Stephen Reckert (1999), fica evidente que, na poesia tradicional ibérica, alguns núcleos de poemas excedem os limites semânticos das suas expressões por conta do simbolismo que ativam. A laranja é uma dessas expressões que circularam desde a tradição anônima por toda a península, passando por trovadores e poetas como Menéndez Pidal ou Gil Vicente até chegar a Lope de Vega, normalmente, utilizada para falar de uma prenda de amor e jogos amorosos. Seguindo os seus passos, posso citar um pequeno poema anônimo, na qual uma niña atira laranjas: "De sus manos hizo un día/ la niña tiro de amores,/ y de naranjas y flores/ balas de su artillería..." (RECKERT, 1999, p. 86). Lope de Vega, por sua vez, muda o cenário de um laranjal português para uma janela em Valência, mantendo tanto a niña quanto as laranjas - "Naranjitas me tira la niña/ en Valencia, por Navidad [...]" (RECKERT, 1999, p. 87). Ainda neste poema de Lope de Vega, a menina parece atirar as laranjas ingenuamente. No entanto, no percurso que Reckert traça, as laranjas tanto são parte de um jogo ingênuo quanto vão mostrando a tentativa de aproximação do pretendente ou mesmo da liberação da tutela da mãe, como se encontra ainda em uma quadra oriunda do Algarve:

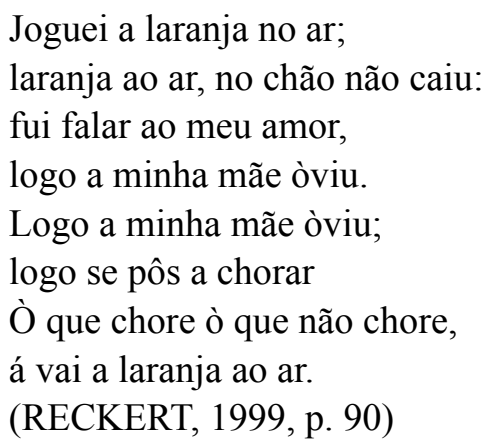

Na verdade, Stephen Reckert (1999) mostra que as laranjas circularam plenamente na escrita da península Ibérica, incluindo a poesia de Lorca, mas que extrapolaram as fronteiras, aparecendo também em um dos Sonetos de Orfeu, de Rilke, ligado a um ritmo de dança popular nada característico do poeta. E mais próximo de nós, no filme brasileiro Orfeu Negro, de Marcel Camus, está o jogo da laranjinha. Na cena, Eurídice brinca distraída com a laranja e Orfeu, receando que ela seja muito jovem para ele, suspeitando dos seus gestos, tira-lhe a laranja e a põe em cima da mesa. O mais importante de todo o estudo sobre a circulação dessa metáfora e de outras frutas é que, no caso da laranja, ela evidencia, pelos vários poemas selecionados, a aceitação do amor e conforme a expressão caminhou ela foi simbolizando o 
desfrutar do amor enquanto os limões, por exemplo, muitas vezes (nem sempre) representavam a sua recusa. Para mim, do mesmo modo que Stephen Reckert entende que os citrinos são suficientemente poderosos para atrair à sua órbita o campo gravitacional de um escritor como Gil Vicente, percebo que a laranja, uma metáfora simples, no poema de Al Berto, pode ser lida como um "resto expressivo", o núcleo da órbita das interrogações diversas que se ligam ao ato de escrever e da tradição literária. Evidentemente não estou interessada em afirmar uma volição na escolha dessa palavra. Se o escritor teve ou não este propósito ao escolhê-la não é questão. $\mathrm{O}$ meu ponto é que a palavra pode remeter a associações psíquicas ligadas à força da função que ela exerceu como metáfora expressiva de um coletivo, sendo um dos elementos dessa força, a localidade ibérica. A palavra pode ter um sentido para cada pessoa, claro. A variação de possibilidades mostra diferenças que podem ser aplicadas aos conceitos - "e um louco, saberá o que é uma laranja?/ e se a laranja cair? o poema? e o poema com uma laranja cair?" (AL BERTO, 2006, p. 35). Cada pergunta concentra conjecturas que retornarão, de certa forma, a decisões em torno de algum modelo de organização cosmológica, um modelo que pode retratar opções formais de composição de mundos. A ambiguidade, no entanto, em poder funcionar como signo arbitrário ou como um "resto expressivo" só reforça ainda mais a noção de uma criatividade poética que se põe a serviço de um jogo que escapa. Talvez, por isso, o "homem que possuía uma cabeça de vidro" podia ver com o "eu" "todo o sistema planetário". Esta cabeça transparente e anterior a qualquer contaminação poderia encontrar os "invisíveis" no interior da língua, as sugestões que no esquema de cortes, saltos e em meio a abismos, tornaram-se uma linguagem de exílio - "o homem que possui uma cabeça de vidro habita o lado de fora/ das muralhas da cidade" (AL BERTO, 2006, p. 36). Fora a cidade, que escorraça o homem da cabeça de vidro, o espaço de uma outra razão pode acolher as forças germinativas da liberdade. Se mostro as possíveis associações da laranja com a metáfora expressiva que ela foi em outro tempo, é para, por um lado realçar a dimensão amorosa do poema, o seu resíduo lírico, invocando uma intimidade que é muito própria do "coração do sonho", ou seja, da partilha de uma dimensão erótica pela imaginação. Por outro, é para reconhecer que mesmo que a imaginação leve ao rumor da tradição, no fundo, os problemas não podem ser superados. Sendo assim, aquela noção de João Barrento de que a poesia contemporânea se afasta da utopia mesmo que possa conter uma dimensão utópica parece trazer alguma luz a essa leitura. O poema se edifica sobre as ruínas da língua ou das línguas, mas abre-se ao "último coração do sonho", mesmo que este não seja mais do que um caminho amoroso pelas vozes que se tencionam com a obscura existência depois de arder. No lugar de uma outra razão, a voz pode circular livremente, indicando apenas perguntas e possibilidades, sem nenhuma revelação. E, por fim, pode partilhar a cantilena com sons que pertencem a outros tempos, desafiando-nos a balbuciar conjuntamente alguma desejável intimidade. 


\section{Conclusão}

Não terá sido minha intenção trazer uma solução para a leitura de poema tão polissêmico, mas apenas acrescentar uma possibilidade de imprimir na imaginação os sons líricos do passado, reativando-os nas negociações que têm sido apresentadas pela crítica contemporânea, principalmente aquela tão afeita à metáfora da luz inteligível que foi expulsando do conceito de uma boa poesia a sentimentalidade, ou hierarquizando esse valor como algo nocivo do qual era preciso se afastar. Esta dicotomia não parece ter efeito sobre escritas que provocam o reconhecimento do "centro frágil e incerto" da escrita, ainda mais, se essa escrita for mesmo uma escrita corpo que deriva de um sujeito rigoroso, cujo desejo é devanear. Se as cidades escritas todas ardem, o coração do sonho parece se oferecer ao fogo transformador, deixando um resíduo na justaposição de "laranja" e através desta palavra, signo resto ou fragmento, salta-se para outra localidade onde o mundo contemporâneo é percebido na sua potencialidade histórica, expressiva e amorosa. A palavra assume complexas conexões que ativam a mobilidade cultural, reencenando imaginários ibéricos em extensa reterritorialização.

\section{Referências}

AL BERTO. O último coração do sonho. Org. Jorge dos Reis-Sá. Vila Nova de Famalicão: Quase Edições, 2006.

ANGHEL, Golgona. Al Berto oral. In: AL BERTO. O último coração do sonho. Org. Jorge dos Reis-Sá. Vila Nova de Famalicão: Quase Edições, 2006. p. 13-31.

Eis-me acordado muito tempo depois de mim: uma biografia de Al Berto. 2. ed. Vila Nova de Famalicão: Quase Edições, 2012.

BARRENTO, João. Geografia imaterial: três ensaios sobre a poesia. Lisboa: Documenta, 2014. BENJAMIN, Walter. Obras escolhidas III. Charles Baudelaire, um lírico no auge do capitalismo. Tradução: José Carlos Martins Barbosa e Hermerson Alves Baptista. São Paulo: Brasiliense, 1995. BLANCHOT, Maurice. O espaço literário. Rio de Janeiro: Rocco, 1987.

. A literatura e o direito da morte. In: A parte do fogo. Tradução: Ana Maria Scherer. Rio de Janeiro: Rocco, 1997. p. 290-330.

CALVINO, Italo. As cidades invisíveis. Tradução: Diogo Mainardi. São Paulo: Companhia das Letras, 1990.

. Seis propostas para o próximo milénio. Lisboa: Teorema, 1998.

JAUSS, Hans Robert. Tradição literária e consciência atual da modernidade. In: OLINTO, Heidrun Krieger (Org.). Histórias de literatura: as novas teorias alemãs. São Paulo: Ática, 1996.

JUNG, Carl G. O homem e seus símbolos. Rio de Janeiro: Nova Fronteira, 1964.

MARTELO, Rosa Maria. Vidro do mesmo vidro: tensões e deslocamentos na poesia portuguesa depois de 1961. Porto: Campo das Letras, 2007. 
MATOS, Olgária C. F. O iluminismo visionário: Benjamin, leitor de Descartes e Kant. São Paulo: Brasiliense, 1993.

O CÉU de Lisboa. Direção: Wim Wenders. Portugal. 1984. 99 min.

PAZ, Octavio. Os filhos do barro. Rio de Janeiro: Nova Fronteira, 1984.

RECKERT, Stephen. Para além das neblinas de novembro: perspectivas sobre a poesia ocidental e oriental. Tradução: Dídia Marques Reckert. Lisboa: Fundação Calouste Gulbenkian, 1999.

ROUANET, Sérgio Paulo. Édipo e o anjo: itinerários freudianos em Walter Benjamin. Rio de Janeiro: Tempo Brasileiro, 1990.

SHORSKE, Carl E. La idea de ciudad en el pensamiento europeo de Voltaire a Spengler, Punto de Vista, Buenos Aires, n. 30, jul./oct., 1987.

WENDERS, Wim. A paisagem urbana. Revista do Patrimônio Histórico e Artístico Nacional, Rio de Janeiro, n. 23, p. 180-189, 1994.

ZAMBRANO, María. A metáfora do coração e outros escritos. 2. ed. Introd. e trad. José Bento. Lisboa: Assírio e Alvim, 2000.

\section{Minicurrículo}

Mônica Simas é doutora e mestre pela PUC-RJ. É professora associada da Universidade de São Paulo. Livre-docente na área de Literatura Portuguesa pela mesma instituição, coordena o Laboratório de Interlocuções a Ásia e o Grupo Macau: literaturas, línguas e culturas, certificado no CNPq. É pesquisadora do CNPq com o projeto Experiência da Orfandade na Literatura de Macau. 